\title{
Karakteristik dan Pemanfaatan Mataair di Daerah Tangkapan Sistem Goa Pindul, Karangmojo, Gunungkidul
}

\author{
Romza Fauzan Agniy, Eko Haryono, Ahmad Cahyadi \\ Departemen Geografi Lingkungan, Fakultas Geografi, Universitas Gadjah Mada \\ Yogyakarta
}

\section{Intisari}

Inventarisasi sumberdaya air termasuk di dalamnya potensi mataair di kawasan karst merupakan hal yang penting. Keterbatasan sumber air permukaan menjadikan mataair memiliki peranan yang penting dalam penyediaan air bersih di kawasan karst. Penelitian ini bertujuan untuk menginventarisasi karakteristik dan pola pemanfaatan mataair di daerah tangkapan air sistem Goa Pindul di Kabupaten Gunungkidul. Data yang dibutuhkan meliputi lokasi mataair, debit mataair dan pemanfaatan mataair di lokasi kajian. Hasil penelitian menunjukkan bahwa, debit terukur mataair di sekitar daerah tangkapan sistem Pindul antara 3,02 liter/detik sampai dengan 63 l/detik dan mataair di sekitar daerah tangkapan sistem Goa Pindul dimanfaatkan untuk berbagai keperluan, meliputi irigasi, mandi, dmencuci dan air minum.

Kata Kunci: Mataair, Karst, Karakteristik, Pemanfaatan

\section{Pendahuluan}

Mataair (spring) merupakan keluaran aliran airtanah yang memusat kemudian muncul di permukaan tanah (Purnama, 2010). Bagi masyarakat, mataair ini sebagai salah satu sumberdaya alam yang bermanfaat untuk memenuhi kebutuhan air. Mataair akan memiliki peranan yang lebih besar pada kawasan karst, karena jarangnya ditemukan sumber air di permukaan (Cahyadi, 2103).

Keterdapatan mataair dipengaruhi beberapa faktor antara lain curah hujan, topografi, struktur geologi, permeabilitas, dan karakteristik akuifernya (Sudarmadji dkk., 2012). Faktor-faktor tersebut berpengaruh pada karakteristik mataair di suatu wilayah yang tentunya akan berpengaruh pada kuantitas, agihan, debit, dan kualitas mataair. Beberapa hal tersebut akan sangat berpengaruh terhadap kemungkinan pemanfaatan yang dapat dilakukan terhadap mataair. 
Pemunculan aliran airtanah secara alamiah dapat berupa mataair ataupun berupa rembesan (seepage). Mataair maupun rembesan selain disuplai dari air hujan juga dapat berasal dari air magmatik maupun air fosil. Besarnya debit mataair sangat tergantung pada besarnya imbuhan yang masuk dan luas wilayah tangkapan dari mataair.

Mataair yang terdapat pada daerah karst memiliki beberapa keunikan antara lain, (1) mataair dengan debit sama, temperature yang sama, kesadahan yang sama pula dapat ditemukan pada mataair karst yang lain, (2) mataair karst biasanya memiliki debit yang besar, dan (3) karakteristik mataair karst lebih dikontrol oleh tingkat perkembangan karst di daerah tersebut (Haryono dan Adji, 2004).

Kawasan karst di daerah tangkapan Goa Pindul memiliki banyak mataair, baik yang sudah dikelola, ataupun yang belum dimanfaatkan dengan baik. Upaya inventarisasi sumberdaya air, termasuk di dalamnya inventarisasi mataair penting dilakukan mengingat kawasan ini saat ini berkembang menjadi destinasi wisata yang sangat maju (Cahyadi dkk., 2011; Suprayogi dkk., 2016). Kemajuan pariwisata akan diikuti dengan peningkatan jumlah kebutuhan air, yang mungkin dipenuhi dari mataair (Cahyadi, 2014; Nurrohmah dkk., 2016; Nurrohmah dan Cahyadi, 2016). Penelitian ini bertujuan untuk mengenali karakteristik dan pemanfaatan mataair di Daerah Tangkapan Sistem Goa Pindul. Lokasi ini terletak di Kecamatan Karangmojo, Kabupaten Gunungkidul.

\section{Metode Penelitian}

\subsection{Data, Alat dan Bahan}

Data yang dibutuhkan dalam penelitian ini terdiri dari data primer dan data sekunder. Data primer dan data sekunder yang dibutuhkan dalam penelitian ini ditunjukkan pada Tabel 1. Selain itu, dibutuhkan beberapa alat survei dan bahan yang digunakan/ membantu untuk pengambilan data dalam penelitian ini. Alat survei yang dibutuhkan untuk mempermudah penelitian disertai dengan fungsi alat ditunjukkan pada Tabel 2. Bahan yang dibutuhkan untuk mempermudah penelitian disertai fungsi bahan ditunjukkan pada Tabel 3. 
Tabel 1. Data yang Dibutuhkan

\begin{tabular}{|c|c|}
\hline Data Primer & Data Sekunder \\
\hline $\begin{array}{l}\text { - Data debit mataair } \\
\text { - } \quad \text { Data pemanfaatan mataair }\end{array}$ & - Peta RBI \\
\hline
\end{tabular}

Tabel 2. Alat Penelitian yang Digunakan

\begin{tabular}{|c|l|l|}
\hline No & \multicolumn{1}{|c|}{ Nama Alat } & \multicolumn{1}{|c|}{ Fungsi } \\
\hline 1 & $\begin{array}{l}\text { GPS (Global Positioning } \\
\text { System) }\end{array}$ & $\begin{array}{l}\text { Mengetahui titik koordinat } \\
\text { pengukuran kedalaman muka } \\
\text { airtanah, titk sumber pencemar dan } \\
\text { sampel airtanah. }\end{array}$ \\
\hline 2 & Pita Ukur/ Meteran & $\begin{array}{l}\text { Mengukur dan menentukan panjang } \\
\text { saluran air dan mengukur tinggi } \\
\text { muka air }\end{array}$ \\
\hline 3 & Ceklist Lapangan & $\begin{array}{l}\text { Mencatat hasil pengamatan dan } \\
\text { pengukuran di lapangan }\end{array}$ \\
\hline 4 & Alat tulis dan Papan Jalan & $\begin{array}{l}\text { Menulis dan membantu pencatatan } \\
\text { data di lapangan }\end{array}$ \\
\hline 5 & Kamera & $\begin{array}{l}\text { Mengambil gambar/dokumentasi } \\
\text { lapangan }\end{array}$ \\
\hline
\end{tabular}

Tabel 3. Bahan Penelitian yang Digunakan

\begin{tabular}{|c|l|l|}
\hline No & \multicolumn{1}{|c|}{ Nama Bahan } & \multicolumn{1}{c|}{ Fungsi } \\
\hline 1. & $\begin{array}{l}\text { Peta Rupa Bumi Indonesia } \\
\text { Lembar Karangmojo skala } \\
1: 25.000\end{array}$ & $\begin{array}{l}\text { Sebagai peta survei lapangan dan } \\
\text { informasi ketinggian tempat. }\end{array}$ \\
\hline
\end{tabular}

\subsection{Teknis Pengumpulan Data}

Data yang dibutuhkan meliputi data lokasi mataair, debit, dan data pemanfaatan mataair di lokasi kajian. Teknis pengumpulan data dalam penelitian ini dijelaskan pada Tabel 4. 
Tabel 4. Teknis Pengumpulan Data Penelitian

\begin{tabular}{|l|l|l|}
\hline No & \multicolumn{1}{|c|}{ Data Penelitian } & \multicolumn{1}{|c|}{ Teknis Pengumpulan Data } \\
\hline 1. & Data debit mataair & $\begin{array}{l}\text { Melakukan pengukuran debit mataiar } \\
\text { dengan metode pelampung dan } \\
\text { volumetric sesuai dengan karakteristik } \\
\text { aliran. }\end{array}$ \\
\hline 2. & Data pemanfaatan mataair & $\begin{array}{l}\text { Kegiatan dilakukan dengan wawancara } \\
\text { kepada responden yang ditemui di } \\
\text { sekitar mataair tersebut. }\end{array}$ \\
\hline
\end{tabular}

\subsection{Teknis Analisis Data}

Teknik analisis atau metode analisis yang digunakan dalam penelitian ini adalah metode analisis deskriptif. Analisis deskriptif dilakukan dengan mendasari nilai hasil perhitungan secara matematis yang telah dijabarkan dalam beberapa rumus sebelumnya. Metode deskriptif ini juga berlaku dalam menjelaskan kenampakan data dalam bentuk-bentuk diagram, kurva ataupun bentuk representatif data lainnya.

\section{Hasil dan Pembahasan}

Daerah tangkapan sistem Pindul terdapat dua zona yakni zona akuifer conduit dan cona akuifer diffuse. Keberadaan mataair ini dijumpai pada zona diffuse, mataair tersebut antara lain Mataair Mudal, Beji, Kali banteng, Jebul, Suruh, dan Ngancar. Mataair yang dapat diukur debitnya yakni Mataair Mudal, Jebul, Suruh, Ngancar.

Mataair Mudal terletak pada zona $49 \mathrm{M}$ koordinat $461115 \mathrm{mT}$ dan $9122285 \mathrm{mU}$, merupakan mataair yang letaknya di hulu dari daerah tangkapan sistem Pindul. Pengukuran debit pada mataair ini dilakukan dengan metode volumetric, karena air meluah secara langsung dari pintu air yang ada di mataair ini. Debit terukur pada mataair ini adalah sebesar 3,02 liter/detik. Mataair Mudal ini digunakan oleh penduduk setempat untuk mencuci dan mengairi lahan persawahan. Mataair Mudal ditunjukkan seperti pada Gambar 1. 


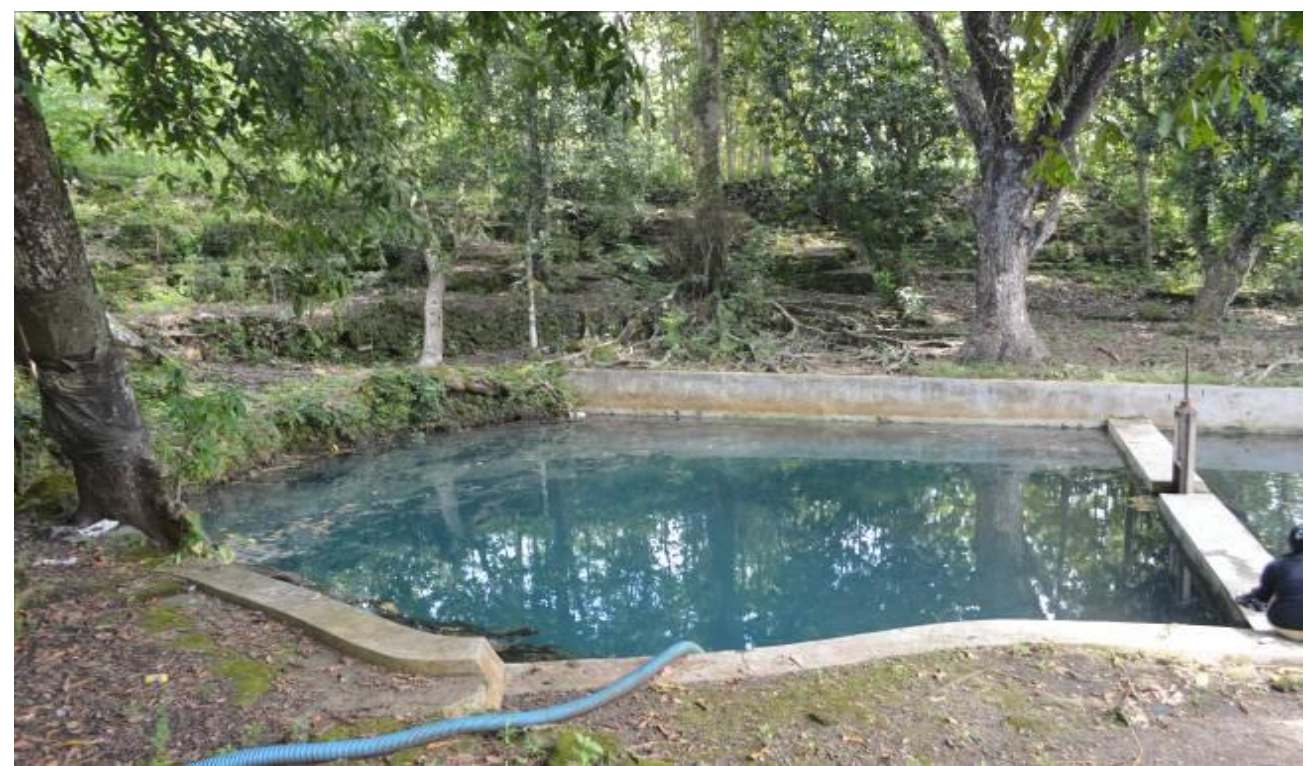

Gambar 1. Mataair Mudal

Mataair Jebul terletak pada koordinat $461030 \mathrm{mT}$ dan $9122757 \mathrm{mU}$ zona $49 \mathrm{M}$, merupakan mataair yang berada dekat dengan junction atau pertemuan aliran dari Mataair Mudal dan Matair Beji. Debit Mataair Jebul diukur dengan metode pelampung. Debit terukur pada mataair ini sebesar $0,044 \mathrm{~m}^{3} /$ detik. Mataair Jebul ditunjukkan seperti pada Gambar 2 ini dimanfaatkan oleh penduduk setempat untuk air minum, mencuci, dan mengairi lahan sekitar.

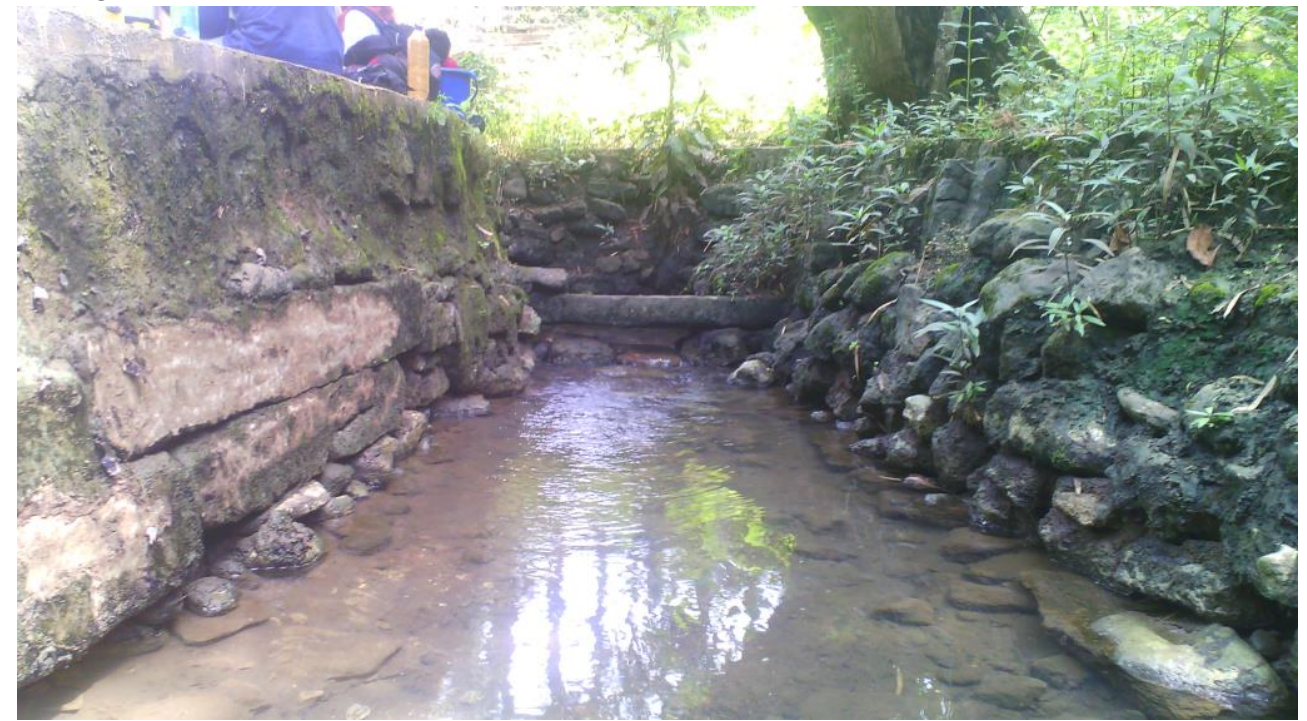

Gambar 2. Mataair Jebul 
Mataair Suruh merupakan seepage atau rembesan yang keluar dari mulut Goa Candi-Suruh dan mengalir ke mulut Goa Suruh-Sioyot, seperti ditunjukkan pada Gambar 3. Mulut Goa Candi-Suruh dan mulut Goa SuruhSioyot merupakan 2 mulut yang saling berhadapan. Mulut goa ini terbentuk oleh adanya collapse doline. Debit mataair Suruh ini diukur dengan metode pelampung. Debit terukur sebesar $0,025 \mathrm{~m}^{3} /$ detik.

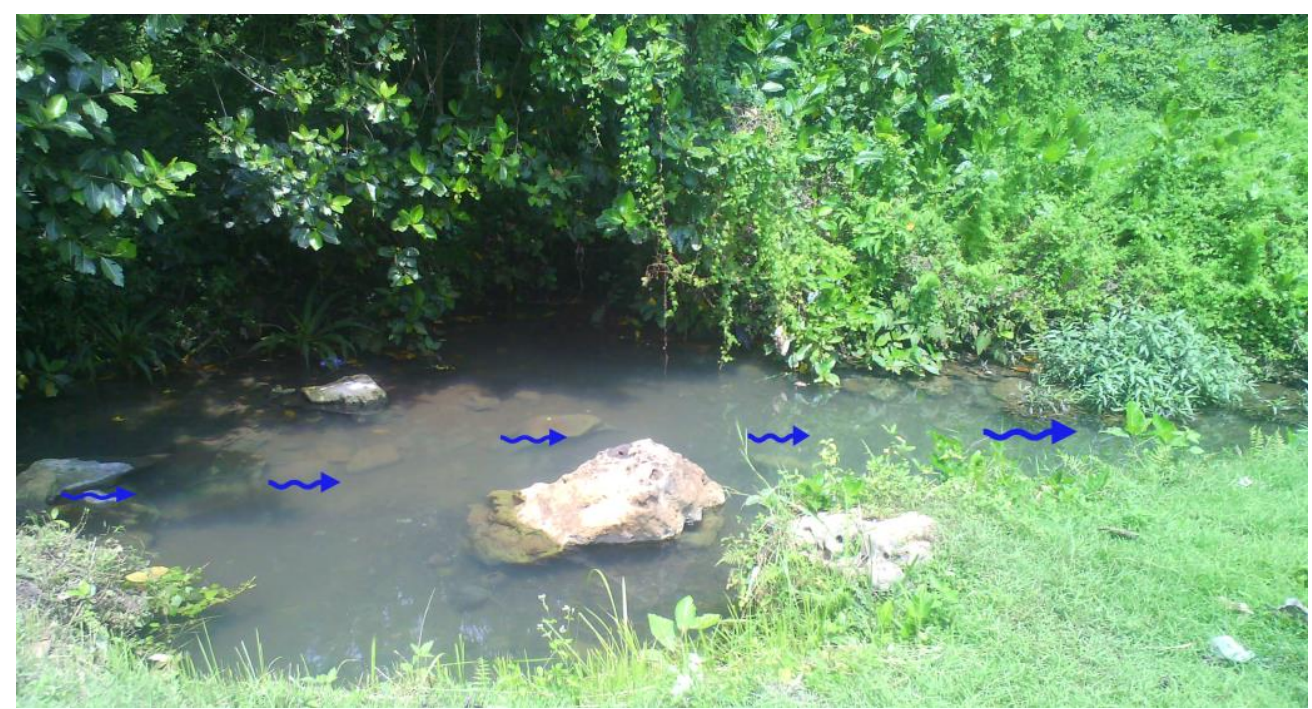

Gambar 3. Rembesan Suruh

Rembesan ini diyakini berasal dari sungai bawahtanah Candi-Suruh, karena pada sistem pergoaan Candi-Suruh ini terdapat lorong dengan kedalaman muka airtanah yang tinggi sehingga pemetaan terhenti, dapat dikatakan rembesan ini merupakan bocoran dari sistem aliran bawahtanah Candi-Suruh. Rembesan ini digunakan oleh masyarakat sekitar untuk mandi dan mencuci.

Mataair Ngancar terletak pada koordinat $461380 \mathrm{mT}$ dan $9123105 \mathrm{mU}$ zona 49M. Mataair ini merupakan bocoran dari sistem pergoaan SuruhSioyot yang dibuktikan dengan keluarnya zat pelacak uranine, yang sebelumnya dilakukan injeksi uranine didalam Goa Sioyot, ditunjukkan seperti pada Gambar 4. Debit Mataair Ngancar dilakukan dengan metode pelampung, yang diketahui debit terukur sebesar $0,063 \mathrm{~m}^{3} /$ detik. Pemanfaatan mataair ini digunakan sebagai air minum. 

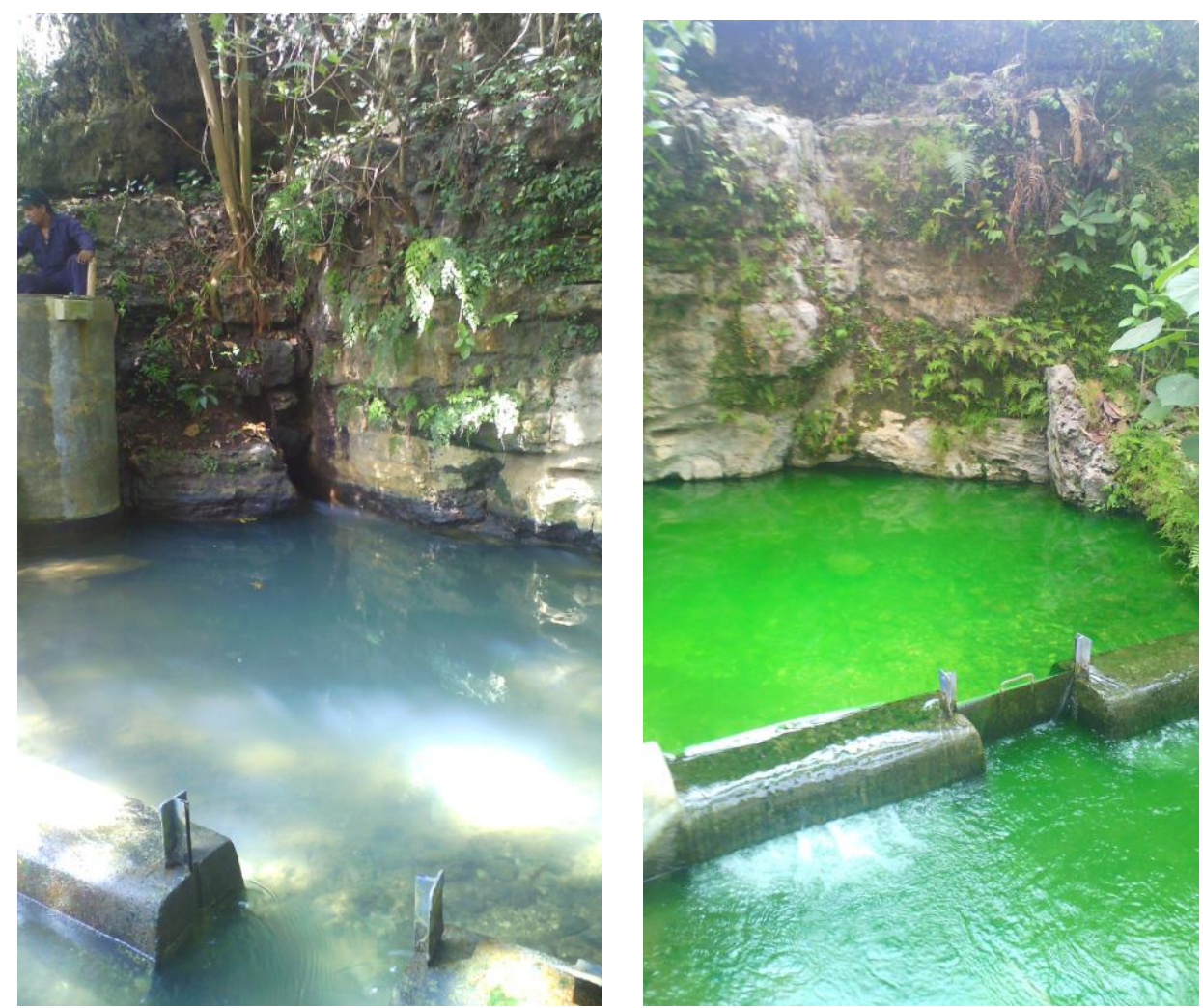

Gambar 4. Mataair Ngancar dan pemunculan zat pelacak uranine

\section{Kesimpulan}

Berdasarkan hasil kajian yang dilakukan, maka disimpulkan beberapa hal berikut ini:

1. Debit terukur mataair di sekitar daerah tangkapan sistem Pindul adalah Mataair Mudal 3,02 liter/detik. Mataair Jebul 0,044 m³/detik. Mataair Suruh 0,025 m³/detik. Mataair Ngancar 0,063 m³/detik; dan

2. Mataair disekitar daerah tangkapan sistem Goa Pindul dimanfaatkan untuk irigasi, mandi, dan mencuci untuk Mataair Mudal, Jebul, dan Suruh serta untuk air minum pada Mataair Ngancar.

\section{Pengakuan}

Penelitian ini merupakan bagian dari hibah Penelitian Unggulan Perguruan Tinggi (PUPT) Kementerian Riset, Teknologi dan Pendidikan Tinggi (Kemenristekdikti) tahun 2016 yang berjudul "Karakterisasi Hidrologi dan Banjir di Sungai Bawah Tanah Goa Pindul untuk Pengelolaan Pariwisata Berkelanjutan Berbasis Manajemen Kebencanaan" dengan nomor kontrak 679/UN1-P.III/LT/DIT-LIT/2016. 


\section{Daftar Pustaka}

Cahyadi, A. Priadmodjo, A. and Yananto, A. 2011. Criticizing The Conventional Paradigm of Urban Drainage. Proceeding The 3rd International Graduated Student Conference on Indonesia. Yogyakarta: Graduate School, Universitas Gadjah Mada.

Cahyadi, A. 2013. Tingkat Pengetahuan Masyarakat Terhadap Keberadaan dan Penyebab Kerusakan sumberdaya Air Sungai Bawah Tanah di Kawasan Karst Gunungsewu. Geomedia, 11(2): 253 - 260.

Cahyadi, A. 2014. Keunikan Hidrologi Kawasan Karst: Suatu Tinjauan. dalam Cahyadi, A.; Prabawa, B.A.; Tivianton, T.A. dan Nugraha, H. 2014. Ekologi Lingkungan Kawasan Karst Indonesia: Mejaga Asa Kelestarian Kawasan Karst Indonesia, Edisi 2. Yogyakarta: Deepublish. Hal: 1 - 13.

Nurrohmah, H.; Sudarmadji dan Cahyadi, A. 2016. Kajian Kekeringan Meteorologis dan Kaitannya dengan Agihan Mata Air di Kabupaten Kulonprogo, Daerah Istimewa Yogyakarta. Prosiding Seminar Nasional Geografi Lingkungan I. Yogyakarta: Badan Penerbit Fakultas Geografi Universitas Gadjah Mada.

Nurrohmah, H. dan Cahyadi, A. 2016. Analisis Pemenuhan Kebutuhan Air Domestik dengan Airtanah di Daerah Aliran Sungai Kayangan Kabupaten Kulonprogo. Prosiding Seminar Nasional II Pengelolaan Pesisir dan Daerah Aliran Sungai. Yogyakarta: Magister Pengelolaan Pesisir dan Daerah Aliran Sungai, Fakultas Geografi Universitas Gadjah Mada.

Purnama, S. 2010. Hidrologi Airtanah. Yogyakarta: Kanisius.

Sudarmadji; Suprayogi, S. dan Setiadi. 2012. Konservasi mataair berbasis masyarakat di Kabupaten Gununngkidul. Yogyakarta: Sekolah Pascasarjana UGM.

Suprayogi, S.; Purnama, S.; Agniy, R.F. dan Cahyadi, A. 2016. Potensi Airtanah Statis di Daerah Tangkapan Air Goa Pindul, Kabupaten Gunungkidul. Prosiding Seminar Nasional Geografi Lingkungan I. Yogyakarta: Badan Penerbit Fakultas Geografi Universitas Gadjah Mada. 
Makalah ini merupakan bagian dari Buku Seri Bunga Rampai dengan Judul "Hidrologi dan Kepariwisataan Kawasan karst Goa Pindul Kabupaten Gunungkidul" dengan Editor Slamet Suprayogi, Setyawan Purnama, Ahmad Cahyadi, Hendy Fatchurohman. Buku ini diterbitkan oleh Badan Penerbit Fakultas Geografi (BPFG) Universitas Gadjah Mada di Yogyakarta Tahun 2016. Makalah ini termuat dalam Halaman 33-41. 